\title{
Entre a figura e 0 abstrato: instâncias do pensamento
}

Eduardo Augusto Alves Almeida(a)

Felipe Goés ${ }^{(b)}$

Classificar obras de arte como figurativas ou abstratas parece tão incompatível com o pensamento crítico contemporâneo quanto outras oposições extremistas às quais fomos conduzidos ao longo do tempo. Real ou virtual, ciência ou ficção, exatas ou humanas, teoria ou prática, razão ou sensibilidade, fato ou imaginação, saúde ou enfermidade, justiça ou impunidade, sujeito ou objeto, público ou privado, somático ou psicológico, políticas de direita ou de esquerda; entre tantos outros exemplos.

artefazparte.com

(b) Artista e arquiteto, formado pela Faculdade

de Arquitetura

e Urbanismo da Universidade Presbiteriana

Mackenzie. Realizou exposições e projetos artísticos em diversas cidades do Brasil. www. fgoesarte.blogspot.com 
A concepção dualista acaba não apenas insistindo nesses territórios utópicos como, também, ignorando o universo de possíveis que habitam o intervalo entre os seus polos - a "zona de indiscernibilidade" de que fala Deleuze ${ }^{1}$, composta por linhas [não exatamente] divisórias tão tênues, pulsantes e permeáveis que atuam como membranas, regulando fluxos de intensidade. Ingênua ilusão, triste engano; o rígido/instituído não se sustenta, ele se esgota no que diz respeito à sua relevância para as múltiplas/facetadas questões que permeiam a atualidade.

[O absolutismo dá conta das sutilezas do mundo? Fosse o absolutismo político, crítico, científico, social... não daria conta porque se aproxima por uma única frente e pretende, com ela, abranger o todo; porque se aproximaria com a resposta pronta, buscando somente a questão que, de alguma maneira, a justifica. Trabalharemos com essa hipótese.]

Entre a abstração e a figuração absolutas, encontra-se uma rica trama de possibilidades existenciais; linhas de força, linhas flexíveis, linhas erráticas, potências. Os extremos dão lugar a pontos de passagem, encontros, conexões, reflexões. Afirmar o absurdo do pensamento fechado, recluso e embrutecido é ignorar que a humanidade se constitui mais de matizes que de dogmas ${ }^{(c)}$, e que sua emancipação se encontra no caminhar, não no ponto de chegada; a emancipação pelo acompanhamento do outro e de seus processos, pela troca de experiências, pela partilha do sensível ${ }^{2}$.

No lugar de verdades, é possível criar discursos fragmentados. Alternativas. Aberturas. Aproximações. Assumir que tudo se enxerga por perspectivas, e que, do objeto em questão, apenas se apreendem alguns aspectos ${ }^{3}$. Estes tampouco pertencem, única e exclusivamente, àquilo que se observa/pesquisa: são ambiguidades oriundas [da colaboração] daquele que olha e do que é olhado. Portanto, todo olhar é, também, um ato criador $^{4}$, uma participação ativa ${ }^{5}$; e se a criação não é absoluta, se não detém uma aura ${ }^{6}$, pode-se dizer que é singular, própria de cada pessoa.

No limite, não se trata da subjetividade de um sujeito em contato com um mundo - é essa relação "homem-mundo" que possibilita a existência de ambos. Em outras palavras, sujeito e mundo passam a existir no instante em que se encontram, e é desse encontro que provém a experiência subjetiva.

Olhar/criar é inventar/dar sentido; viver é um processo de doação e formação, além de apreensão e expectativa. Colocar-se à disposição do outro, à disposição do mundo; deixar-se atravessar, fluir com eles. Olhar implica transformar - o arredor e a si. Não somente fazer 'com' o outro, mas possibilitar, ao outro, fazer, colaborar com seu processo de descoberta e emancipação. Promover, prioritariamente, o seu direito de fazer, tanto quanto lugares afeitos à prática. Instaurar espaços de encontro: interfaces. Espaços abertos ao diálogo - no lugar então ocupado pelo silêncio incontestável da verdade e seus guardas opressores, sempre prontos para a defesa. E para o ataque.

\author{
(c) Embora, muitas vezes, \\ as relações sociais se \\ organizem conforme \\ dogmas em vez de \\ matizes, ignorando estes \\ últimos, colocando-os \\ à margem, tentando \\ dominá-los com uma \\ política de violência \\ oficial e capacitada.
}


늃ㅇ

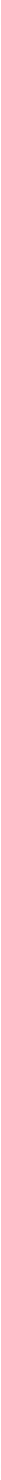

Pintura 146 (acrílica e guache sobre tela), 2012 


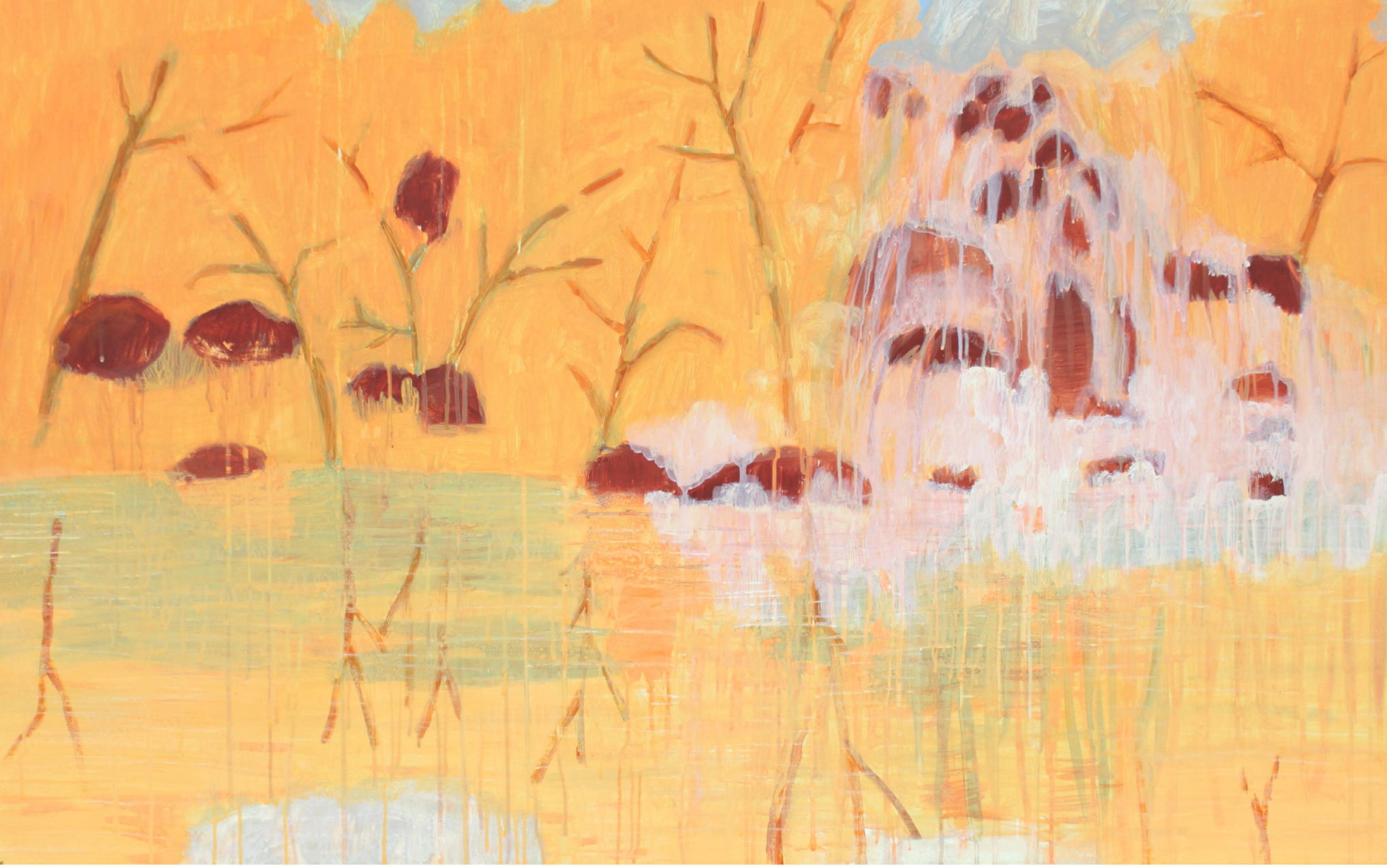


. 윯

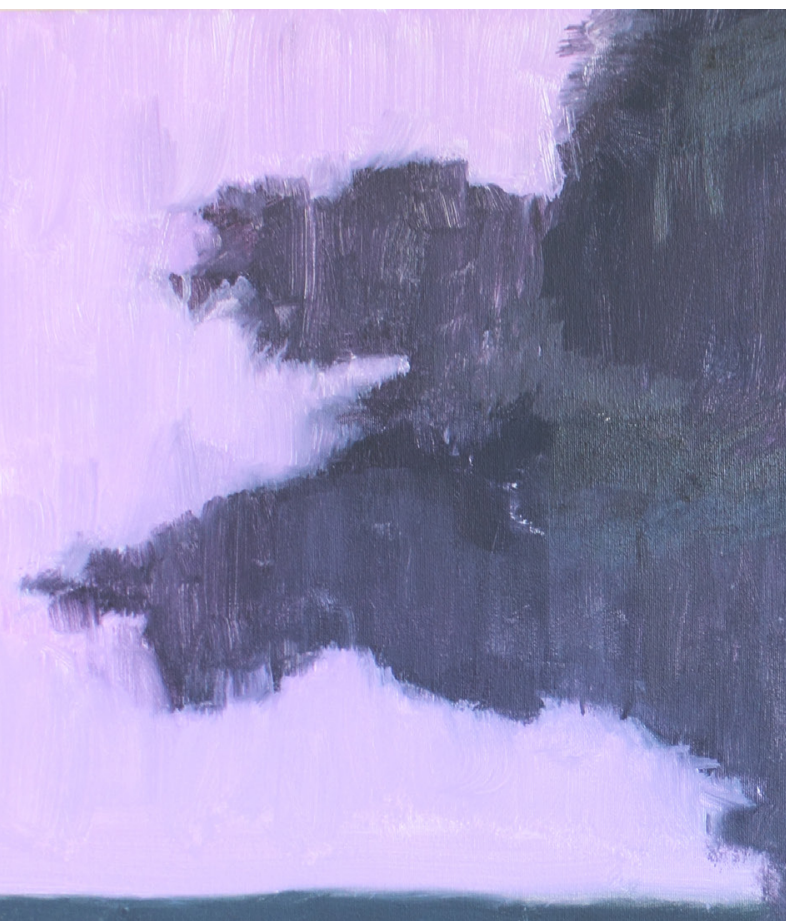

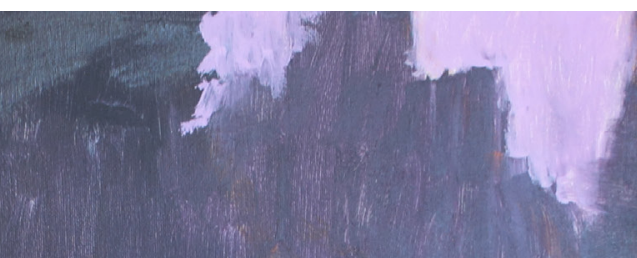

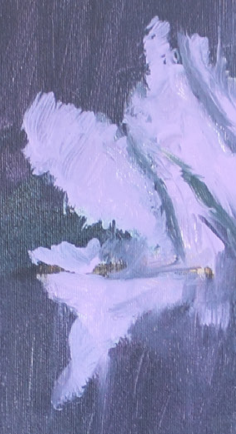

(3)

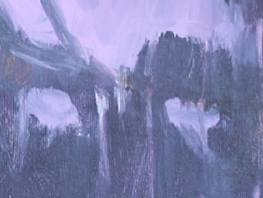

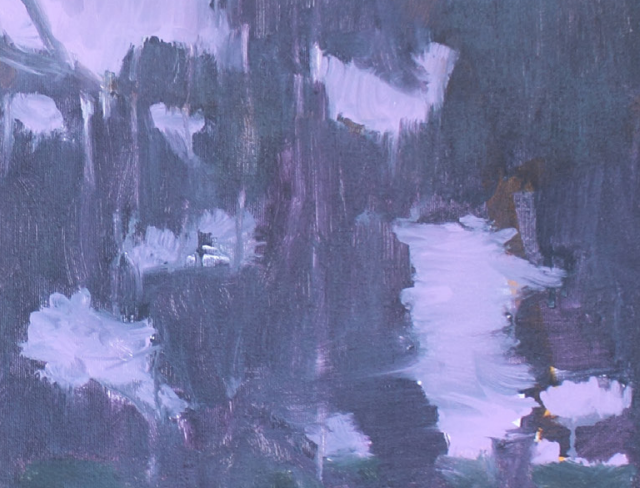

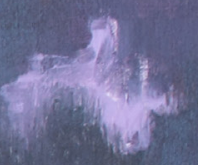

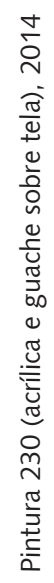

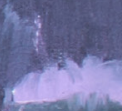




\section{Perspectivas ficcionais}

Uma pintura dita 'abstrata' oferece 'significados abstratos' e, também, 'concretos', assim como a pintura dita 'figurativa'. Trata-se de instâncias da experiência, da relação com a arte, do conhecimento de mundo. Instâncias do pensamento que se depositam como camadas de tinta, ocultando parte do que antes predominava na tela, acrescentando nova possibilidade à composição, estabelecendo novas estruturas e relações.

Essa pintura pode ser batizada com nome que remeta a algo concreto e provocar irrupções de 'pensamentos figurativos' (narrativas, lembranças de fatos...); do mesmo modo, uma paisagem dita 'figurativa' pode se apresentar com nome 'abstrato' e ocasionar sensações difíceis de serem verbalizadas sem que a tradução comprometa sua essência ${ }^{(d)}$, sem que a clareza da elucidação ofusque suas cores e texturas - sentimentos alheios à lógica dita 'científica'.

[Estaria a figura mais próxima da ideia de 'verdade' enquanto a abstração se enamoraria pela 'virtualidade'? Ou ambas seriam aspectos de uma realidade com estrutura ficcional, para citar Žižek ${ }^{7}$; ou de um real que precisa ser ficcionado para ser pensado/assimilado, conforme acredita Rancière ${ }^{2}$ ?]

Outra hipótese: o mundo se apresentaria a nós por meio de estruturas ficcionais. Isso significa que nada existiria de forma definitiva - tudo seria apreendido conforme a cultura de quem apreende, e o real nada mais seria do que um consenso limitado a um grupo de pessoas, um local, uma tradição etc.; em outras palavras, tudo seria, em certa medida, inventado, ficcionado.

Vale esclarecer que essa ficção não se enquadra no duelo 'verdade x mentira'; ela pertence a outro plano no qual estão imersas tanto a concepção da verdade quanto a da mentira, portanto, ambas seriam também espécies de ficção dadas num contexto específico.

A partir de Žižek e Rancière, é factível pensar na ficção - numa certa ideia de ficção - como um possível método de apreensão do contemporâneo; de serem arte e estética ferramentas de questionamento de certas realidades e, no limite, da própria ideia de 'realidade'; e de ser o próprio contemporâneo um conceito ao invés de uma medida - ou seja, uma maneira de pensar demandas ainda relevantes que nos atravessam em campo expandido, tão abrangentes quanto quiserem ser, em vez de continuidade linear da [tradicional cronologia] da História da Arte. Portanto, tratar-se-ia de uma metodologia: um estudo de certa ficção, da arte e da estética contemporâneas como métodos de analisar aspectos daquilo que chamamos de realidade, de produzir uma crítica em relação a ela e, desse modo, de propor resistências.

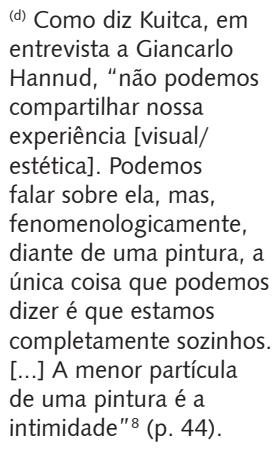

(d) Como diz Kuitca, em entrevista a Giancarlo Hannud, "não podemos compartilhar nossa experiência [visual/ estética]. Podemos falar sobre ela, mas, fenomenologicamente, diante de uma pintura, a única coisa que podemos dizer é que estamos completamente sozinhos. [...] A menor partícula de uma pintura é a intimidade"8 (p. 44). 
(e) Para Bauman, "os estranhos tipicamente modernos foram o refugo do zelo de organização do estado. Fo à visão da ordem que os estranhos modernos não se ajustaram. [...] Os estranhos exalaram incerteza onde a certeza e a clareza deviam ter imperado. Na ordem harmoniosa e racional prestes a ser constituída não

havia nenhum espaço - não podia haver nenhum espaço - para os 'nem uma coisa, nem outra'"9 (p. 28). Tal estranheza, assim como a incerteza proveniente dela, deveria ser anulada, extinguida, com propósito de tornar a sociedade 'pura', de fazê-la sã e salva.

\section{Ilusão perigosa}

A polarização pode parecer acolhedora, afinal. E, por isso, traiçoeira. Ela dispõe de espaço para o sim e para o não, para o certo e o errado; oferece o conforto de ter amigos e inimigos bem distintos, fáceis de reconhecer; o conforto da certeza. Entre trancos e barrancos, ambos coexistem, e a existência de um acaba por depender do outro. Só não há espaço para sobreviver entre os polos, e nisso consiste o perigo que, oriundo da Modernidade, ainda opera nos dias atuais. No pensamento moderno, não existem outras possibilidades entre o cientificismo da verdade e o misticismo da natureza. Os que acreditam nelas tornam-se estranhos ${ }^{(e)}$, malvistos, excluídos, perseguidos por polícias da ordem, com seus uniformes assassinos. Excluídos da constituição do Estado, ainda que este se pretenda democrático. "Uma anomalia a ser retificada", diz Bauman' (p. 30). E explica: "Em suas buscas de constituição da ordem, o estado moderno tratou de desacreditar, de repudiar e erradicar les pouvoirs intermédiaires das comunidades e tradições". 
(f) Bauman utiliza o termo 'pós-moderno' para se referir ao período que sucede

a Modernidade, e

que representa o esgotamento destas ideias. Esse período se confunde com o vivido atualmente, uma vez que não existe uma fronteira clara delimitando seu fim. No caso deste artigo, não cabe distinguir pós-moderno de contemporâneo, uma vez que a discussão é ampla. Para nós, aqui, "atual, pós-moderno e contemporâneo" têm, aproximadamente, o mesmo significado que deve bastar para a discussão proposta. Mais importante seria questionar: o que resta de Moderno no pensamento que circula nas ruas, nas mesas dos bares, na administração do Estado nas relações trabalhistas, no contato com outras pessoas, em especial, as estranhas, estrangeiras, diferentes daquilo que consideramos 'normal' ou 'real'?
Nesse sentido, aquele suposto acolhimento oferecido pela polarização moderna revela-se fascista - uma política de aniquilação das diferenças [ou das possibilidades de existência dessas diferenças] não previamente instituídas, de dissidências, transgressões etc. Seu projeto construtivo se pauta na destruição em outras palavras, para sanar é preciso exterminar; é preciso erradicar qualquer condição de incerteza. Porque a incerteza atenta contra a segurança (moral, militar, física...). Porque a incerteza não condiz com a ideia de pureza.

Enquanto, em revés, a certeza se pauta na exatidão, nos contornos precisos, na rigidez do método científico. Tanto que "os primeiros grandes inventos que marcam a modernidade são instrumentos de medida, e os primeiros grandes inventores são fabricantes de relógios, óculos e mecânicos de oficina" ${ }^{10}$. Essa condição determinante nos levou à Era dos Extremos, denominação do "breve século XX"11, que denuncia certa falência do pensamento moderno. Ou, melhor dizendo, trata-se da crítica de certo lugar a que a Modernidade chegou, levada pelas ondas do capitalismo e tendo, enfim, instituído/dogmatizado aquilo que seria ruptura [tanto objeto de ruptura quanto a atitude de romper], contrariando seus próprios princípios fundadores, como a 'destruição criativa' das Vanguardas artísticas. Tendo o maravilhamento com a máquina desembocado na destruição em massa, no esvaziamento das relações interpessoais e, no limite, na banalização da vida.

Por sua vez, "as oposições que nessa outra experiência [moderna] asseguram e sancionam o significado do mundo, e da vida vivida neste, perdem na nova experiência [atual ${ }^{(\dagger)}$ muito de seu significado, bem como muito de seu potencial heurístico e pragmático"9 (p. 37). Abrir espaço para novas potências aumenta, também, a complexidade dos casos e inviabiliza generalizações. A organização vira desordem, a sensação de segurança desemboca em incertezas; fica evidente certo medo de dissolução da ordem instituída.

\footnotetext{
No entanto, ao lado do colapso da oposição entre a realidade e sua simulação, entre a verdade e suas representações, vem o anuviamento e a diluição da diferença entre o normal e o anormal, o esperável e o inesperado, o comum e o bizarro, o domesticado e o selvagem - o familiar e o estranho, "nós" e os estranhos. Os estranhos já não são autoritariamente pré-selecionados, definidos e separados, como costumavam ser nos tempos dos coerentes e duráveis programas de constituição da ordem administrados pelo estado. Agora eles são tão instáveis e proteicos como a própria identidade de alguém, e tão pobremente baseados, tão erráticos e voláteis. ${ }^{9}$ (p. 37)
}

Em tempos de apagamento de fronteiras e valorização das nuances, cabe rever a organização do mundo e a noção de sujeito que o habita, assim como o impasse entre os polos individual e social, público e privado, normal e estranho, realidade e ficção, figurativo e abstrato. Essa nova paisagem permanece borrada, indefinível e impura. Permanece dissolvida, e, na dissolução, encontra novas formas de composição. 
CRIAÇÃO

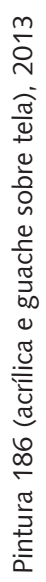




\section{Um método para chamar de contemporâneo}

"O paradigma da ciência moderna encontra-se calcado na razão, na consciência, no sujeito soberano, no progresso e na totalidade do mundo. [...] Tendo como meta abordar a natureza essencial das 'coisas', a partir da noção de verdade", explica Romagnoli'12 (p. 166). Enquanto o paradigma contemporâneo se pautaria numa "humildade epistemológica, ao não perseguir a verdade; a busca de ferramentas úteis para o entendimento do mundo e o abandono da ideia de um lugar privilegiado a partir do qual podemos compreender definitivamente as relações que nos circundam"12 (p. 168). 
(g) Vale a pena conferir as pesquisas da matemática contemporânea, que receberam mais evidência e popularidade com a medalha Fields conquistada pelo brasileiro Artur Avila em meados de 2014 $\mathrm{Na}$ edição especial da revista Piauí dedicada ao tema, tanto ele quanto outros colegas da área revelam que o pensamento matemático busca encontrar certa beleza nas formas impuras do mundo, e que lida com abstrações, 'ficções científicas' e interrogações da natureza muito próximas da poesia, e, afinal de certo conceito de estética - ao contrário da racionalidade intransigente que se poderia associar a esse ramo da ciência ${ }^{13}$ (h) $\mathrm{O}$ artista norteamericano James Turrell, por exemplo, dedicou sua carreira a pesquisar o fenômeno da luz e a maneira como ela é percebida pelos sentidos humanos, gerando/ inventando o mundo como o conhecemos. Para isso, baseia-se em astronomia e física experimental, utiliza equipamentos científicos como projetores de alta intensidade espaços precisamente modificados com objetivo de apreender e modificar a incidência da luz solar. Mais informações podem ser obtidas diretamente no site do artista, disponível em: http:// jamesturrell.com
Seria possível classificar o homem, nos dias atuais, como abstrato ou figurativo sem trair aspectos inerentes ao ser? E a ciência que produz, muitas vezes, tão afeita à $\operatorname{arte}^{(\mathrm{g})}$ ? $\mathrm{E}$ a arte que inventa, por vezes mais efetiva em suas descobertas do que a ciência ${ }^{(h)}$ ? É possível afirmar a pureza da ciência, da arte, do homem, dos pensamentos?

Cabe, ainda, uma última questão: é plausível classificar o homem - e todas as suas criações -, cedendo à generalização, ignorando o que há de mais brutalizante nela?

Última hipótese: talvez a demanda atual almeje fazer conviver as diferenças, as incertezas e as possibilidades de existência oriundas daquele imenso fosso que separava as ambivalências modernistas. Da aridez e da rigidez daquele [em tese] vazio. Aprender a enxergar o obscuro no excesso de claridade, o impuro no excesso de sanidade, o obs-ceno na cena representada bem diante dos nossos olhos, o factível nas utopias. Habitar as heterotopias de que fala Foucault ${ }^{14}$.

Tudo que existe é ao mesmo tempo indissociável e irredutível: a música não é matemática, mas é todinha matemática. Mas seria um erro dizer que a música se reduz à matemática. Inversamente, na matemática, as bases do próprio cálculo decorrem do imaginário, do poético. A indissociabilidade e a irredutibilidade existente entre todas as coisas nos leva a crer que a renúncia à unificação ou à simplificação final não é nem provisória nem uma regra de boa conduta. ${ }^{15}$ (p. 50)

Nem exatamente par nem totalmente ímpar; vivemos no 'entre'. Basta olhar ao redor e perceber que o mundo aceita ser visto assim, e revela os gradientes de que é constituído; é assim a paisagem que nos cerca, ainda que alguns evitem o esforço, preferindo enxergar somente céu ou somente inferno. Manchas de cor que escorrem pela tela formam tanto uma paisagem abstrata quando concreta - a pintura se abre a um universo ficcional ao mesmo tempo em que constitui a própria realidade onde se insere; uma narrativa de fatos e, também, o próprio fato. Confunde o aqui e o acolá, insistindo no ambíguo. Diferentemente do híbrido, formado por ambos os extremos, o ambíguo é nem um nem outro; é o intervalo, a fenda, o meandro e suas nuances.

Assim é a paisagem que ajudamos a compor; e aceitar suas camadas de significados deve estar na ordem do dia daquele que se pretende contemporâneo, que ouve as demandas do agora, que está determinado a pesquisar em meio a essa complexa indeterminação estabelecida entre o absolutismo da verdade e a inconsistência da ficção. Pesquisar com rigor, porém sem dogmas, com persistência, porém sem opressão, circulando pelas redes de possíveis sem dar mais "uma volta a essas reviravoltas que sustentam infindavelmente o mesmo maquinário" 5 (p. 48), que alimentam o velho sistema da crítica e anticrítica, que não conseguem se desvencilhar da verdade justificada pela oposição à mentira. Pesquisar com a consciência de que não se produz nada mais do que leituras do mundo; não se faz nada além de acrescentar uma pincelada à grande representação da vida humana. 
CRIAÇÃO

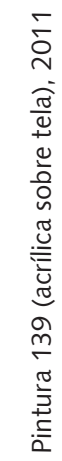

224 (อ) Interface comunicação saúde educaçã̃o 2015; 19(52):211-26 


\section{Colaboradores}

Os autores Eduardo Augusto Alves de Almeida e Felipe Góes participaram, igualmente, da elaboração do artigo. Eduardo deu a forma final ao texto, redigindo-o e revisando-o. Felipe Góes incorporou excertos da sua obra artística. A discussão foi feita em conjunto. A proposta representa ideias consensuais de ambos os autores.

\section{Referências}

1. Deleuze G. A literatura e a vida. In: Deleuze G. Crítica e clínica. São Paulo: Ed. 34; 1997. p. 11-17.

2. Rancière J. A partilha do sensível: estética e política. São Paulo: Ed. 34; 2005.

3. Almeida EAA. Aspectos da estruturação do self de Lygia Clark: perspectivas críticas [dissertação]. São Paulo (SP): Programa Interunidades em Estética e História da Arte, Universidade de São Paulo; 2013.

4. Duchamp M. O ato criador (1957). In. Battcock G, organizador. A nova arte. São Paulo: Perspectiva; 2004. p. 71-74.

5. Rancière J. O espectador emancipado. São Paulo: Martins Fontes; 2012.

6. Benjamin W. A obra de arte na era de sua reprodutibilidade técnica. In: Benjamin W. Magia e técnica, arte e política. São Paulo: Brasiliense; 1994. p. 169-196. (Obras escolhidas, v. 1).

7. Žizek S. De Hegel a Marx... e de volta a Hegel! Palestra oferecida no SESC Pinheiros, São Paulo, em 8 de março de 2013. [acesso 2013 Nov 17]. Disponível em: http://www.sescsp.org.br/online/videos/26_SLAVOJ+ZIZEK+DE+HEGEL + A + MARX+

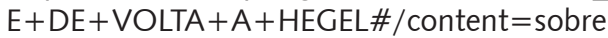

8. Kuitca G. Filosofia para princesas. São Paulo: Pinacoteca do Estado de São Paulo; 2014. (Catálogo de exposição realizada entre 17 de julho e 2 de novembro de 2014).

9. Bauman Z. O mal-estar da pós-modernidade. Rio de Janeiro: Zahar; 1998

10. Theophilo R. A transdisciplinaridade e a modernidade [Internet] [acesso 2014 Nov 20]. Disponível em: http://www.sociologia.org.br/tex/ap40.htm

11. Hobsbawn EJ. Era dos extremos: o breve século XX: 1914-1991. São Paulo: Companhia das Letras; 1995.

12. Romagnoli RC. A cartografia e a relação pesquisa e vida. Psicol Soc. 2009; 21(2):166-73.

13. Salles JM, editor. Artur tem uma medalha - a história da maior conquista da ciência brasileira. Rev Piauí. 2014; ed. esp.

14. Foucault M. Outros espaços (1984). In: Motta MB, organizador. Estética: literatura e pintura, música e cinema. Rio de Janeiro: Forense Universitária; 2006. p. 411-420.

15. Burnham TF; Fagundes NC. Transdisciplinaridade, multirreferencialidade e currículo. Rev FACED. 2001; (5):39-55. 
Por meio de texto e pintura, este artigo visa discutir a possibilidade de habitar certo intervalo entre polos extremistas, e, a partir da estética, rever paradigmas dos pensamentos moderno e contemporâneo.

Palavras-chave: Estética. Pintura. Modernidade. Contemporâneo. Arte figurativa e abstrata.

\section{Between the figure and the abstract: instances of thought}

With text and painting, this article aims to discuss the possibility of inhabiting certain interval between extreme poles and to review, from the aesthetic, some paradigms of modern and contemporary thoughts.

Keywords: Aesthetics. Painting. Modernity. Contemporary. Figurative and abstract art.

\section{Entre la figura y el abstracto: instancias del pensamiento}

Con texto y pintura, este artículo tiene como objetivo discutir la posibilidad de habitar cierto intervalo entre polos extremos y revisar, desde la estética, algunos paradigmas del pensamiento moderno y contemporáneo.

Palabras clave: Estética. Pintura. Modernidad. Contemporáneo. Arte figurativo y abstracto.

Recebido em 22/11/14. Aprovado em 15/12/14. 